\title{
Idiopathic scrotal calcinosis: report of 2 cases, and review of pathogenesis and factors that determine patients' acceptance of surgical treatment
}

This article was published in the following Dove Press journal:

Clinical, Cosmetic and Investigational Dermatology

\author{
Adeolu Oladayo Akinboro' \\ David Adekunle Onilede ${ }^{2}$ \\ Taiwo Olabimpe Babatunde ${ }^{3}$ \\ Sebastine Oseghae Oiwoh' \\ Oreoluwa Adeola Suleiman ${ }^{3}$ \\ Olatunde Peter Olabode ${ }^{4}$ \\ 'Dermatology Unit, Department \\ of Internal Medicine, Ladoke \\ Akintola University of Technology, \\ Ogbomoso and LAUTECH \\ Teaching Hospital, Ogbomoso, \\ Oyo, Nigeria; ${ }^{2}$ Plastic Surgery Unit, \\ Department of Surgery, LAUTECH \\ Teaching Hospital, Ogbomoso, \\ Oyo, Nigeria; ${ }^{3}$ Department of \\ Histopathology, LAUTECH Teaching \\ Hospital, Ogbomoso, Oyo, Nigeria; \\ ${ }^{4}$ Department of Internal Medicine, \\ LAUTECH Teaching Hospital, \\ Ogbomoso, Oyo, Nigeria
}

\begin{abstract}
Introduction: Idiopathic scrotal calcinosis is a benign and rare disease of the scrotal skin that presents as solitary or multiple asymptomatic calcified nodules in the absence of systemic disorders of calcium/phosphorus balance.

Case reports: We report the management of 2 cases and review the literature with comments on factors that determine acceptance or otherwise of surgical treatment. Our patients were 29 and 33 years old and presented with nodular scrotal lesions. Through multiple elliptical incisions, all nodules were excised from patient 1, but patient 2 refused surgery. Reasons for rejection included fear of future reproductive performances. Histology shows calcium deposition in basophilic globules of varying sizes and shapes within the reticular dermis, multinucleated giant cells, dense collagenous stroma, areas of fibrosis, and sparse lymphocytic infiltrate.

Conclusion: In the management of idiopathic scrotal calcinosis, factors that determine acceptance of surgical treatment could include impaired quality of life, reduced self-esteem, fear of future sexual dysfunction, and development of complications.
\end{abstract}

Keywords: idiopathic scrotal calcinosis, surgery, treatment

\section{Introduction}

Idiopathic scrotal calcinosis (ISC) is a rare and benign disease of the scrotal skin that presents with solitary or multiple, asymptomatic calcified nodules or papules on the scrotum, which usually appear at a young age or in early adulthood in the absence of systemic disorder of the calcium/phosphorus metabolism. ${ }^{1}$ In a few published cases, the intradermal nodules tend to increase in size and number over time and could be associated with pruritus, feeling of heavy sensation, discharge of a white chalky material, or a combination of all these symptoms. ${ }^{1-4}$ Lewinski ${ }^{5}$ described ISC initially in 1883, and Hutchinson ${ }^{6}$ added further descriptions in their report. About a century later, Shapiro et $\mathrm{al}^{7}$ suggested the name "Idiopathic scrotal calcinosis" after exclusion of the presence of epithelial lining, residual cysts, lipid, or organisms in the histology. More than 120 cases of ISC have been described in the literature; however, the pathogenesis remains unclear. ${ }^{8}$

Concerning the etiology of ISC, the last 40 years have witnessed the suggestions of more hypotheses than ever before. ${ }^{8}$ ISC could be truly idiopathic as suggested by Shapiro et al ${ }^{7}$ or it could be due to dystrophic calcification following calcium deposition on epidermal cysts according to Karabulut et al; ${ }^{9}$ it could be related to eccrine cysts of the scrotum; or it could result from dystrophic calcification in the dartos muscle. ${ }^{8}$ However, there is uniform agreement that ISC is characterized by calcium deposits

\footnotetext{
Correspondence: Adeolu Oladayo Akinboro

Dermatology Unit, Department of Internal Medicine, Ladoke Akintola University of Technology, Ogbomoso and LAUTECH Teaching Hospital, PMB 4007, Ibadan-llorin Road, Ogbomoso, Oyo, Nigeria

Tel +234 8I 36872240

Email deolustevelIII@yahoo.com
} 
of various sizes that are surrounded by a granulomatous reaction. ${ }^{7-10}$ Surgery is the only treatment recommended for ISC, and it allows for pathologic confirmation of the disorder. ${ }^{11}$ The indications for surgery include relief of symptoms with preservation of scrotal tissue in mind. Studies have described 1-stage, and multistage technique to elliptical excision of ISC. ${ }^{1,12}$ We present 2 cases of ISC, review the literature, and discuss the reasons why surgical intervention is accepted or not among people with ISC.

\section{Case I}

A 29-year-old male was referred to our clinic with an 8 -year history of multiple painless scrotal nodules that had progressively increased in size and number. The few $0.5-1$ cm subcutaneous papules on both hemi-scrotal tissues were sometimes itchy. The patient denied a history of scrotal trauma or ingestion of any medication before the onset of a papule. There was no urethral discharge, penile ulceration, or inguinal swelling. The patient noticed some of the papules disappeared after discharge of a whitish or chalk-like substance from them. He had no previous history of sexually transmitted infection. As the number and size of the nodules were increasing, he became uncomfortable, embarrassed, and did not want others to see the lesion. He reported that he was not sexually active and had avoided intimate relationships because of his scrotal lesions. There was no history of any chronic illness or medication use. Physical examination showed multiple palpable but painless dark brown intradermal nodules on the scrotum. The calcified nodules involved both hemi-scrotum, but were preponderantly on the left. No other skin lesion was noticed. The phallus was circumcised and the testes were palpable and grossly normal. Laboratory evaluation revealed normal serum phosphorus and a slightly lower calcium level. The patient underwent excision of the lesions near the median raphe under local anesthesia using a single elliptical incision. Other individual nodules on both hemi-scrotums were excised individually and closed separately to preserve some uninvolved skin and to allow for adequate scrotal skin closure. The defects were closed using 3-0 prolene suture interrupted technique (Figure 1). There were no postoperative complications to date, and the patient had an excellent scrotal cosmetic outcome.

Histology sections revealed calcium deposition, and basophilic globules of varying sizes and shapes within the reticular dermis. There was an occasional scalloped appearance, with some of the smaller fragments surrounded by multinucleated giant cells and a sparse lymphocytic infiltrate. In between the globules, there were dense collagenous stroma and areas of fibrosis that were seen, and a fibrous capsule surrounded the entire lesion. The histopathologic diagnosis was "ISC", and no sign of epithelial lining was found in the nodules (Figures 2-5).

\section{Case 2}

A 33-year-old male was referred to our clinic with a 20-year history of multiple asymptomatic, currently nondischarging scrotal nodules that had progressively increased in size and number. He denied an antecedent history of trauma to the scrotal sac. He had no associated fever, no inguinal swelling, or urethral discharge. Despite the increase in the number and size of the nodules, there was no itching, and he was not affected by the swelling. The patient brought to the clinic one off-white stone-like material that was extruded from one of the lesions in the recent past (Figure 6). The patient was sexually active. Examination showed an apparently healthy young man, not in any form of distress. The only significant findings on examination were multiple palpable dark yellow and brown intradermal calcified nodules involving the ventral and lateral surface of the scrotal sac (Figure 6). There was no deformity in his penis. Laboratory evaluation revealed normal serum phosphorus and calcium level. The patient, however, declined surgical intervention because of fear of the impact of the surgery on his sexual function and future reproductive life.

\section{Discussion}

ISC is a rare but benign disease of the scrotal skin that presents with solitary or multiple calcified nodules. Epidemiologically, most ISC presentations occur in the third to fourth decade of life, following years of insidious onset without any systemic disorder of the calcium/phosphorus metabolism. ${ }^{1}$ To the best of our knowledge, 10 cases of ISC have been reported from Nigeria, 2 cases in infants (6 and 8 months, respectively) and others in adults. ${ }^{13-16}$ The ISC nodules are typically yellowish-white or dark in color, consisting of grouped or individual nodules of the variable number containing calcium and phosphate deposits in the scrotal skin. The nodules are usually firm and asymptomatic, but could be itchy or painful, and the patient can present with chalk white discharge following an episode of infection. ${ }^{11}$

The etiology of ISC has been the subject of long-term controversy. Initially, ISC was believed to be truly idiopathic since no cellular elements, cysts, lipid, or organisms were found within the calcified nodules. ${ }^{1,2,5,7,13-16}$ However, some later studies showed that ISC takes its origin from the dystrophic calcification of the epidermoid cysts, ${ }^{14}$ epithelial 

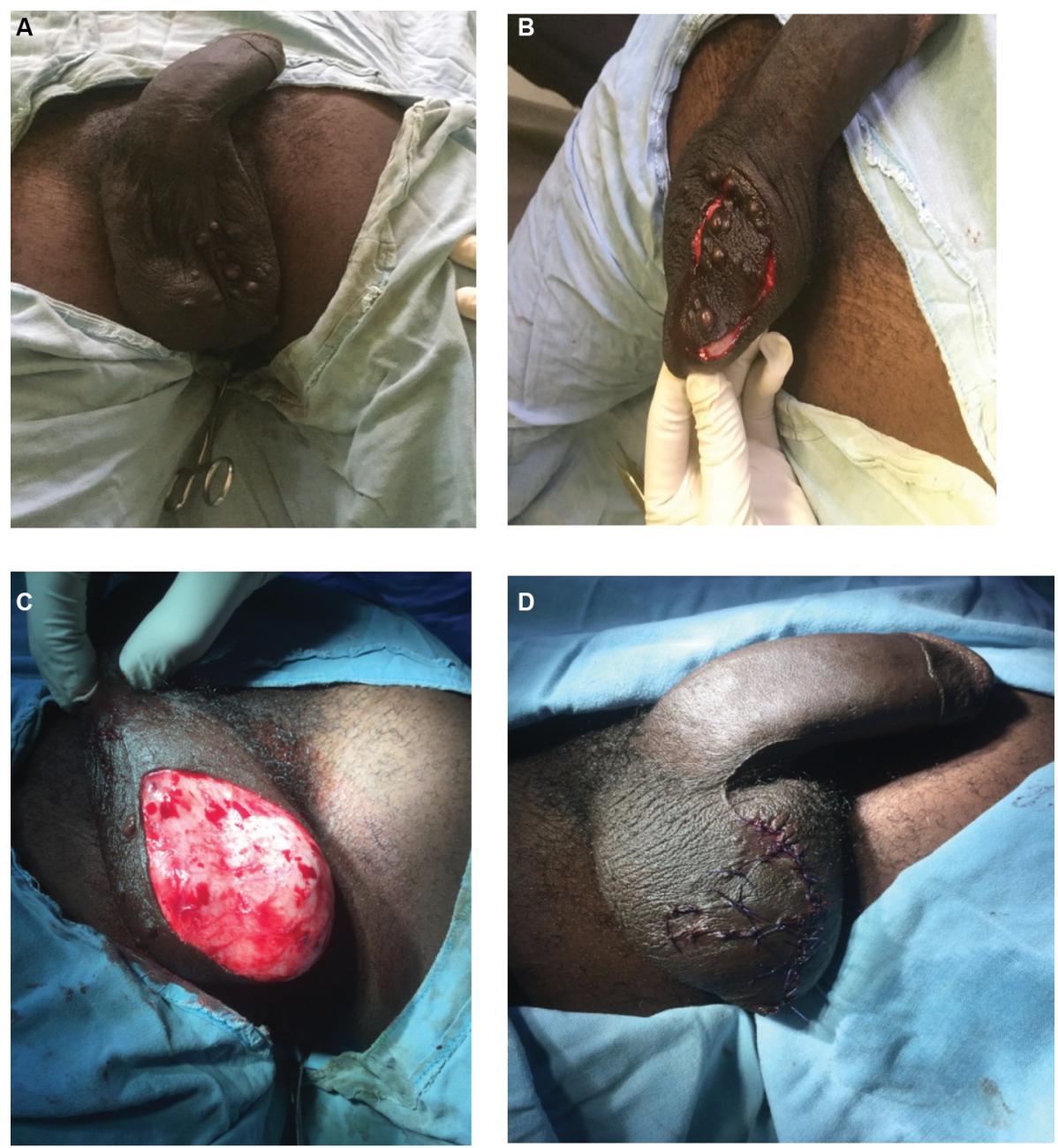

Figures I Patient I: preoperative (A), intraoperative (B and C), and postoperative (D) views of idiopathic scrotal calcinosis.

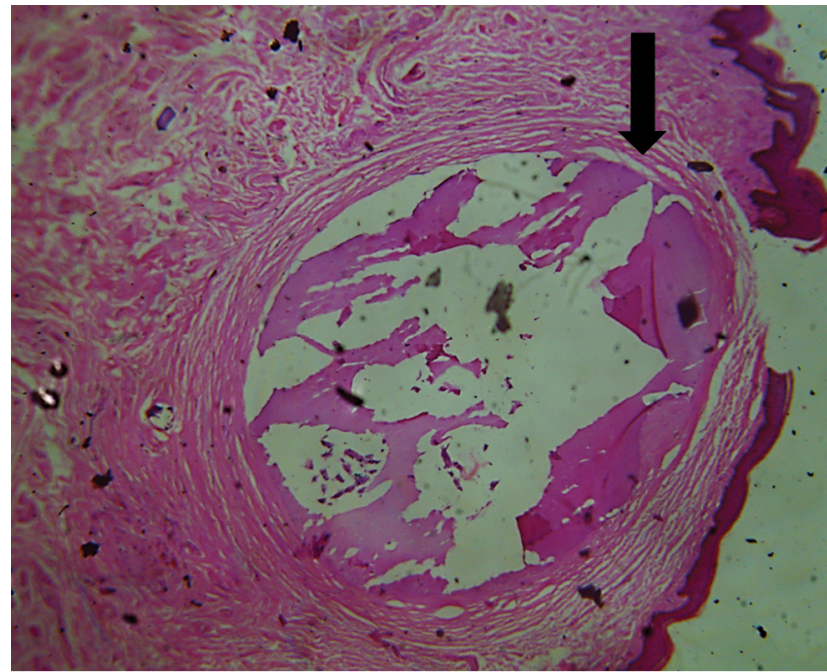

Figure 2 Photomicrograph of a case of idiopathic scrotal calcinosis showing intraluminal calcifications, shown by the black arrow (hematoxylin and eosin, 100x).

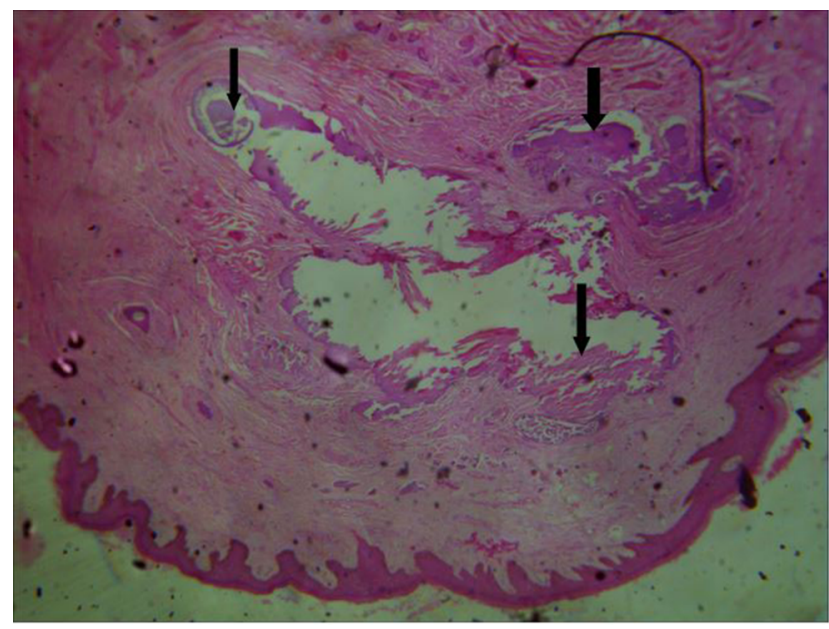

Figure 3 Photomicrograph of a case of idiopathic scrotal calcinosis showing nodules of calcific material (black arrows) embedded in dense connective tissue matrix (hematoxylin and eosin, 100x). 


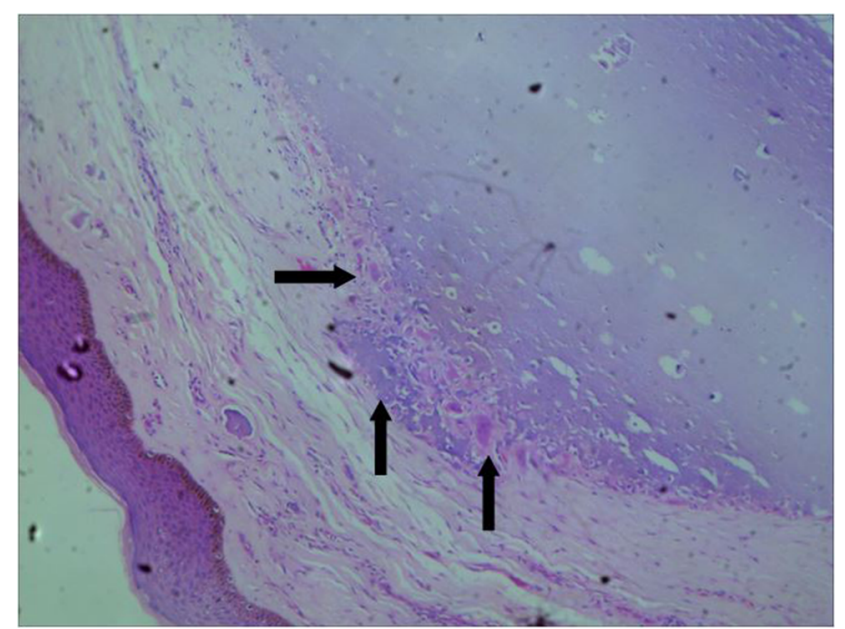

Figure 4 Photomicrograph of a case of idiopathic scrotal calcinosis showing calcified nodule embedded in connective tissue matrix.

Notes: This nodule is partly rimmed by foreign body giant cell reaction as shown by the black arrows (hematoxylin and eosin, 100×).

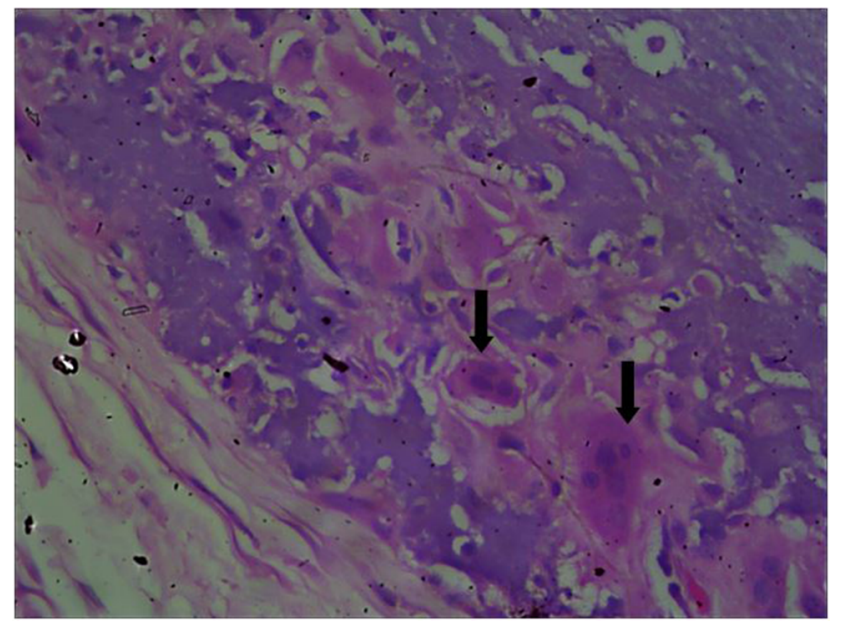

Figure 5 Photomicrograph of a case of idiopathic scrotal calcinosis. showing foreign body giant cell reaction.

Note: The giant cells are shown by the black arrows (hematoxylin and eosin, 400x).

wall, and keratin fibers. ${ }^{9}$ More recently, Pabuççuoğlu et $\mathrm{al}^{4}$ speculated that the degeneration and necrosis of dartos muscle played a prominent primary role in the etiopathogenesis of ISC following which dystrophic calcification occurred. However, our findings are not in support of the hypothesis which suggests the origin of ISC from degeneration of dartos muscle, as the excision of the lesion showed that the encapsulated nodule occurred separately above the dartos fascia. Our histology showed no epithelial lining or cysts, which is similar to prior reports from Nigeria ${ }^{13-16}$ and other regions. ${ }^{12}$ However, pathologic analysis of samples by Redondo et al ${ }^{17}$ showed that some of the scrotal calcinosis arose from epidermal cyst, and some of the samples fulfilled the criteria for ISC. From all these evidence, we opined that the ISC could be the end stage of a single disease that started from multiple etiologies. Reports from isolated and some large surgical anatomical reports support this view. $3,4,8,10,11,17$ More careful tissue examination in a large sample size study would be necessary to address the issue of the etiology and pathogenesis of ISC.

Surgery has been the only recommended mode of treatment for ISC. One-stage excision has been shown to lead to patient satisfaction and improvement in quality of life and self-esteem. ${ }^{18}$ In the present case, a wide excision of the majority of the nodules was done around median raphe, and other individual distant nodules were excised. Although single-stage excision has shown good outcome, this might not be possible in all situations as the distribution and extent of lesions vary widely. Multistage excision of ISC in the first patient also led to a subjective improvement in the quality of life, satisfaction, and motivation to commence his sexual life. We believe that conservation of scrotum to ensure the satisfactory function of the testicle, spermatogenesis, and good cosmetic outcome should be the ultimate guide for a surgical approach. Scrotal sac reconstruction may be required in extensive and severe diseases. ${ }^{16}$ The indications for surgical excision include cosmetic concerns, severe pruritus, and ulceration. ${ }^{16}$ The second patient, who was slightly older, single, and was educated to a tertiary level, decided to refuse surgery and cope with the disease despite counseling. One factor responsible for his rejection was the fear that the surgery could harm his sexual performance and future reproductive life. In this part of the world, the cost of surgery and fear of death, usually due to ignorance, prompt a negative response to the offer of surgery as a treatment modality. Therefore, it was not a surprise that the second patient with ISC refused the offer of surgical treatment, especially after reassurance that his ISC was not life threatening.

\section{Conclusion}

ICS is a rare, benign, and nodular disorder of the scrotum which is of unknown etiology. The impairment of quality of life, self-esteem, and fear of sexual dysfunction could determine acceptance of surgical treatment, in addition to the development of complications and for cosmetic reasons.

\section{Ethical statement}

Written informed consent was provided by the patients to have their case details and images published. 

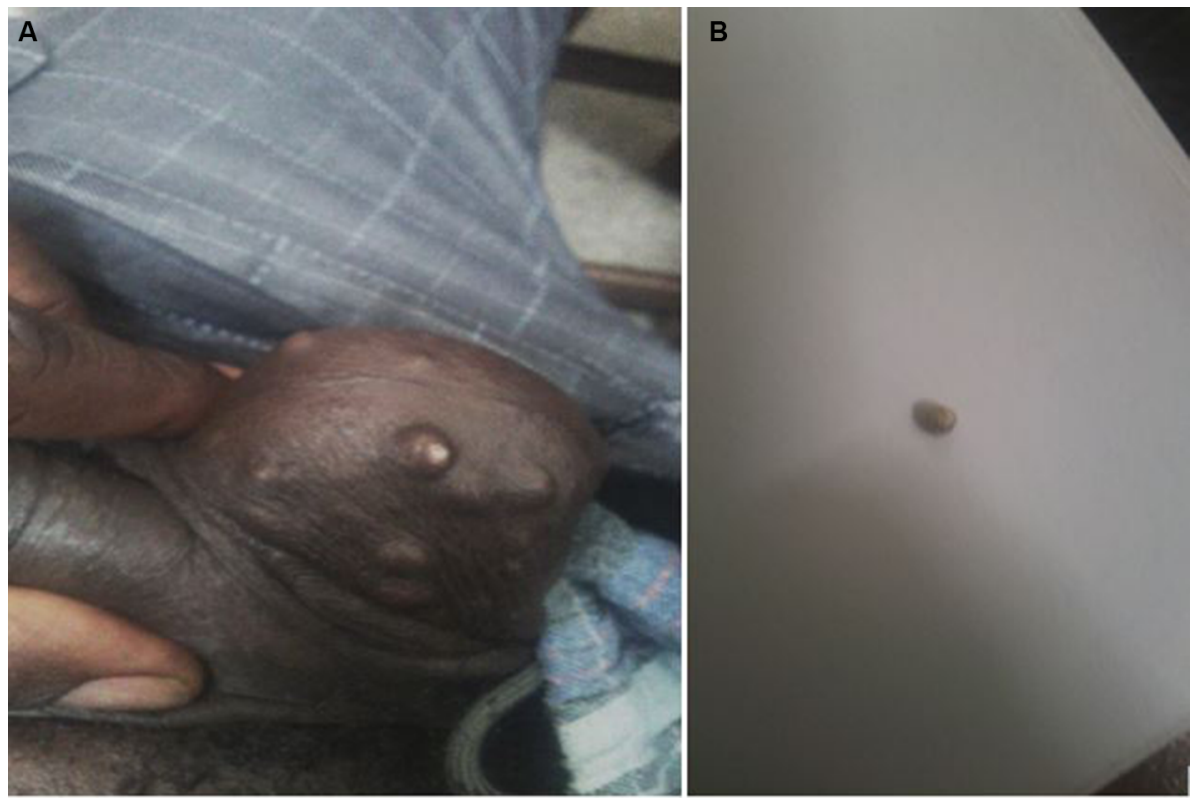

Figure 6 Patient 2: images of idiopathic scrotal calcinosis (A) and I extruded calcium stone (B).

\section{Disclosure}

The authors report no conflicts of interest in this work.

\section{References}

1. Pompeo A, Molina WR, Pohlman GD, Sehrt D, Kim FJ. Idiopathic scrotal calcinosis: a rare entity and a review of the literature. Can Urol Assoc J. 2013;7(5-6):e439-e441.

2. Özgenel GY, Kahveci R, Filiz G, Ozcan M. Idiopathic scrotal calcinosis. Ann Plast Surg. 2002;48(4):453-454.

3. Saad AG, Zaatari GS. Scrotal calcinosis: is it idiopathic? Urology. 2001;57(2):365.

4. Pabuççuoğlu U, Canda MS, Guray M, Kefi A, Canda E. The possible role of dartoic muscle degeneration in the pathogenesis of idiopathic scrotal calcinosis. Br J Dermatol. 2003;148(4):827-829.

5. Lewinski HM. [Lymphangiome der Haut mit verkalktem Inhalt]. Virchows Arch. 1883;9:371-374. German.

6. Hutchinson J. Illustrations of Clinical Surgery. Vol 2. Philadelphia, PA: Balkiston; 1882.

7. Shapiro L, Platt N, Torres-Rodriguez VM. Idiopathic calcinosis of the scrotum. Arch Dermatol. 1970;102(2):199-204.

8. Saladi RN, Persaud AN, Phelps RG, Cohen SR. Scrotal calcinosis: is the cause still unknown? J Am Acad Dermatol. 2004;1:39.

9. Karabulut YY, Kankaya D, Şenel E, Dölek Y, Uslu A, Sertçelik A. Idiopathic scrotal calcinosis: the incorrect terminology of scrotal calcinosis. G Ital Dermatol Venereol. 2015;150(5):495-499.
10. Ito A, Sakamoto F, Ito M. Dystrophic scrotal calcinosis originating from benign eccrine epithelial cysts. Br J Dermatol. 2001;144(1): 146-150.

11. Song DH, Lee KH, Kang WH. Idiopathic calcinosis of the scrotum: histopathologic observations of fifty-one nodules. J Am Acad Dermatol. 1988;19(6):1095-1101.

12. Khallouk A, Yasami OE, Mellas S, Tazi MF, El Fassi J, Farih MH. Idiopathic scrotal calcinosis: a non-elucidated pathogenesis and its surgical treatment. Rev Urol. 2011;13(2):95-97.

13. Ibrahim M, Ibrahim GK, Mohammad MA, et al. Calcinosis of the scrotum in children: report of two cases and review of the literature. Arch Int Surg. 2013;3:142-146.

14. Yusuf SM, Uloko AE, Sani MU, Mijinyawa SM, Mohammed AZ. Idiopathic scrotal calcinosis; a rare scrotal tumour: a case report and review of literature. Niger J Med. 2010;19(4):482-484.

15. Yahya H, Rafindadi AH. Idiopathic scrotal calcinosis: a report of four cases and review of the literature. Int J Dermatol. 2005;44(3):206-209.

16. Tela UM, Ibrahim MB. Scrotal calcinosis: a case report and review of pathogenesis and surgical management. Case Rep Urol. 2012;2012:475246.

17. Redondo Martínez E, Rey López A, Sánchez Lobo V. Patología Quirúrgica del escroto. Análisis de una serie de 56 casos [Surgical pathology of the scrotum. An analysis of a series of 56 cases]. Arch Esp Urol. 1999;52(1):11-16. Spanish.

18. Noel W, Hersant B, Meningaud JP. Traitement chirurgical de la calcinose scrotale en un temps [One-staged surgical technique for scrotal calcinosis]. Prog Urol. 2016;26(3):176-180. French.

\section{Clinical, Cosmetic and Investigational Dermatology}

\section{Publish your work in this journal}

Clinical, Cosmetic and Investigational Dermatology is an international, peer-reviewed, open access, online journal that focuses on the latest clinical and experimental research in all aspects of skin disease and cosmetic interventions. This journal is included on PubMed. The manuscript management system is completely online

\section{Dovepress}

and includes a very quick and fair peer-review system, which is all easy to use. Visit http://www.dovepress.com/testimonials.php to read real quotes from published authors 